\title{
A study on inventory model with negative exponential demand and probabilistic deterioration under backlogging
}

\author{
Sumit Saha ${ }^{\mathrm{a}}$ and Nabendu Sen ${ }^{\mathrm{a}^{*}}$
}

${ }^{a}$ Department of Mathematics, Assam University, Silchar, 788011, India

\begin{tabular}{l}
\hline C H R O N I C L E \\
\hline Article history: \\
Received July 2, 2016 \\
Received in revised format \\
September 10, 2016 \\
Accepted October 212016 \\
Available online \\
October 26 2016 \\
\hline Keywords: \\
Inventory \\
Probabilistic deterioration \\
Exponential demand \\
Optimality \\
\hline
\end{tabular}

A B S T R A C T

\begin{abstract}
The present study is an attempt to develop an inventory model for deteriorating items with negative exponential demand. Shortages are allowed with partial back logging. This model is different from the existing models where deterioration is a function of time. Accordingly, three different types of probabilistic deterioration functions have been considered to find the associated decision variables and also to make comparisons among them. The optimality is illustrated with numerical values of system parameters and the graphical representations are given to depict the trend. The necessary observations in obtaining optimal values of decision variables are analyzed in the light of the practical aspect of the developed model. Finally, considering the numerical values of system parameters, sensitivity analyses are carried out to study the effect of changes in most important system parameters.
\end{abstract}

(C) 2017 Growing Science Ltd. All rights reserved.

\section{Introduction}

Inventory problems are almost common to all spheres of industrial as well as business houses. It has become an area of research to academicians and practitioners. Considering its usefulness in real world problems, particularly in business and industry, researchers have taken an interest and extended their thoughts in obtaining optimal solutions for different decision variables under considerations for inventory problems. In the theory of inventory control, models are developed by considering the parameters like demand, deterioration, allowing shortages and without shortages. Among the developed models in inventory control, models with deterioration have significantly drawn the interest of researchers. In this regards, a number of researchers have put forward different models under different assumptions. Ghare and Schrader (1963) first discussed the effect of deterioration. Shah and Pandey (2009) developed an inventory model with time dependent deterioration when demand depends on displayed stock level and frequency of advertisement via media. Sarkar and Sarkar (2013) also developed an inventory model with time dependent deterioration. Bhunia and Shiakh (2011) discussed an inventory model for deteriorating items. In their model deterioration was considered to follow Weibull distribution. Sarkar and Sarkar (2013) discussed EMQ model for deteriorating items. In this study, deterioration was taken as probabilistic. Further Sarkar (2013) developed production inventory

\footnotetext{
* Corresponding author

E-mail address: nsen08@yahoo.com (N.Sen)

(C) 2017 Growing Science Ltd. All rights reserved. doi: $10.5267 /$ j.uscm.2016.10.006
} 
model for deteriorating items in a two-echelon supply chain management and applied algebraic approach to estimate the minimum cost. Palanivel et al. (2015) developed an inventory model for deteriorating items under permissible delay in payment and the rate of deterioration as probabilistic towards minimizing the total cost. Palanivel and Uthayakumar (2014) developed an economic production quantity model with inflation and time value of money for probabilistic deteriorating items. Singh and Pattnayak (2013) presented an inventory model with trapezoidal type demand rate and Weibull distribution deterioration. Kumar and Rajput (2016) also considered deterioration rate as probabilistic. Latha and Uthayakumar (2014) in their developed model considered different types of continuous deterioration function with shortages and partial back logging. Basu and Sinha (2007) discussed inventory model with Weibull deterioration and demand rate as a linear function of time. Dave and Patel (1981) considered deterioration as a constant fraction of on hand inventory. By taking linear trend in demand under two different assumptions on backlogging, Goswami and Choudhuri (1992) discussed inventory model. Goyal and Giri (2001) presented a review of advances in inventory modelling for deteriorating items. Wee and Law (1999) in their study used discounted cash-flow approach for deteriorating items in order to obtain optimal production and pricing policy to maximize profit. Manna and Choudhuri (2006) developed inventory model for deteriorating items with demand rate as ramp type function of time. Khurana and Chakraborty (2016) gave optimal ordering and pricing

policy for deteriorating items incorporating price and stock sensitivity demand and partial back logging during shortages. A generalized dynamic programming for inventory items with Weibull distributed deterioration proposed by Chen (1998) with assumption of time proportional demand and shortages under influence of inflation and time discounting. Wang and Chen(2001) extended the model of Hariga (1995) by taking finite rates of production and deterioration, demand was allowed to very over finite planning horizon with variable replenishment cycle. Shah (1998) made an attempt to develop discretetime probabilistic inventory model for deteriorating items to determine optimal cycle time when vendor announces price escalation from a future date. Cheng et al.(2011) proposed an optimal replenishment policy for inventory model with demand rate as trapezoidal function of time and allowing partial back logging. Chou and Julian (2015) studied the inventory model of Ouyang et al. (2013) and provided new solution procedure to show that interior minimum exist and unique and pointed out that there are two local minimums on the boundaries. Liao and Huang (2010) developed inventory model for deteriorating items to obtain optimal cycle time under permissible delay in payment and constraints on ware house capacity. Lee and Dye (2012) formulated inventory model with stock dependent demand and technology cost as one of the decision variables under the assumption of shortages and partial backlogging depending on the length of waiting time for next replenishment. The contribution of Tripati and Kumar (2014), Bhunia et al. (2015) for deteriorating items is significant. However, inventory model with probabilistic deterioration and negative exponential demand has not been reported yet.

In our present investigation through inventory modelling, the attempt has been made to study the effect on optimality when deterioration is considered as different probability functions and then to make comparisons.

\section{Model formulation}

To develop the proposed inventory model, the following assumptions are made:

\subsection{Assumptions}

i) Demand rate is exponentially declining.

ii) Shortages are allowed and partially backlogged.

iii) Holding cost is independent of time.

iv) Deterioration is time proportional.

v) There is no repair of deteriorating items.

vi) Lead time is zero. 


\subsection{Notations}

i) $h=a \quad(a>0)$ holding cost per unit per unit time

ii) $\theta(t)=\theta t, \theta$ is the rate of deterioration and $0<\theta<1$

iii) $D(t)=A e^{-\alpha t}$

iv) $C_{0}$ is the ordering cost.

v) $C_{s}$ is the shortage cost per unit per unit time.

vi) $C$ is the unit cost of the item

vii) $\beta$ is the backlogging rate , $0 \leq \beta<1$

viii) $T$ is the cycle length

ix) $I_{0}$ is the maximum inventory level in $(0, T)$

x) $S$ lost sale cost per unit.

\section{Formulation and Solution of the model}

Based on the above assumptions, the differential equation representing the inventory situation during the interval $\left[0, t_{1}\right]$ is

$$
\frac{d I_{1}(t)}{d t}+\theta t I_{1}(t)=-A e^{-\alpha t}, 0 \leq t \leq t_{1}, \text { with } I_{1}(0)=I_{0}, I_{1}\left(t_{1}\right)=0
$$

We solve Eq. (1) by the series solution method. Let

$$
I_{1}(t)=\sum_{n=0}^{\infty} d_{n} t^{n}
$$

Differentiating w.r. t. $t$,

$$
\frac{d I_{1}(t)}{d t}=\sum_{n=1}^{\infty} n d_{n} t^{n-1}
$$

Using Eq. (1a) and Eq. (1b) in Eq. (1) we have

$$
\sum_{n=1}^{\infty} n d_{n} t^{n-1}+\theta t \sum_{n=0}^{\infty} d_{n} t^{n}=-A \sum_{n=0}^{\infty} \frac{(-\alpha)^{n} t^{n}}{n !}
$$

Equating the coefficients of like powers of $t$,

$$
\begin{aligned}
& d_{1}=-A \\
& d_{2}=A \frac{\alpha}{2 !}-\frac{\theta}{2} d_{0} \\
& d_{3}=-A \frac{\alpha^{2}}{3 !}+\frac{\theta}{3} A \\
& d_{4}=A \frac{\alpha^{3}}{4 !}-\frac{\theta}{4} A \frac{\alpha}{2 !}+\frac{\theta^{2}}{8} d_{0} \\
& d_{5}=-A \frac{\alpha^{4}}{5 !}+\frac{\theta}{5} A \frac{\alpha^{2}}{3 !}-\frac{\theta^{2}}{15} A
\end{aligned}
$$


Putting $d_{i}$ 's in (1a) and neglecting the terms containing $\theta^{2}$

$$
I_{1}(t)=d_{0}+A\left(-t+\frac{\alpha t^{2}}{2 !}-\frac{\alpha^{2} t^{3}}{3 !}-\cdots \cdots\right)-\frac{\theta}{2} d_{0}+A\left(\frac{\theta}{3} t^{3}+\frac{\theta}{4}\left(\frac{\alpha}{2 !}\right) t^{4}+\frac{\theta}{5}\left(\frac{\alpha^{2}}{3 !}\right) t^{5}+\cdots \cdots\right)
$$

Since $I_{1}(0)=I_{0}$, Eq. (1d) gives

$d_{0}=\frac{2 I_{0}}{(2-\theta)}$

Therefore, after simplification Eq. (1d) can be written as

$$
I_{1}(t)=I_{0}+\frac{A}{\alpha}\left(e^{-\alpha t}-1\right)+A \theta \sum_{n=3}^{\infty} \frac{\alpha^{n-3} t^{n}}{(n-2) ! n} .
$$

The rate of change of the inventory during the shortage period $\left[\mathrm{t}_{1}, \mathrm{~T}\right]$ is governed by the differential equation

$$
\begin{aligned}
& \frac{d I_{2}(t)}{d t}=-A \beta e^{-\alpha t}, t_{1} \leq t \leq T_{1}, I_{2}\left(t_{1}\right)=0 \\
& I_{2}(t)=\frac{A \beta}{\alpha}\left(e^{-\alpha t}-e^{-\alpha t_{1}}\right)
\end{aligned}
$$

Holding cost is given by

$$
H C=\int_{0}^{t_{1}} h(t) I_{1}(t) d t=I_{0} t_{1} a-\frac{a A}{\alpha^{2}}\left(e^{-\alpha t_{1}}-1+\alpha t_{1}\right)+A a \theta \sum_{n=3}^{\infty} \frac{\alpha^{n-3} t_{1}^{n+1}}{(n-2) ! n(n+1)} .
$$

Shortage cost during the period $\left[\mathrm{t}_{1}, \mathrm{~T}\right]$ is given by

$$
S C=-C_{s} \int_{t_{1}}^{T} I_{2}(t) d t=-C_{s} \frac{A \beta}{\alpha}\left[\frac{\left(e^{-\alpha t_{1}}-e^{-\alpha T}\right)}{\alpha}+e^{-\alpha t_{1}}\left(t_{1}-T\right)\right] \text {. }
$$

Lost sale cost during the shortage period is calculated as

$$
L S C=S \int_{t_{1}}^{T}(1-\beta) D(t) d t \quad=S \int_{t_{1}}^{T}(1-\beta) A e^{-\alpha t} d t=\frac{S A(1-\beta)}{\alpha}\left(e^{-\alpha t_{1}}-e^{-\alpha T}\right) .
$$

The purchase cost is

$$
P C=C\left[I_{0}+\int_{t_{1}}^{T} \beta D(t) d t\right]=C\left[I_{0}+\int_{t_{1}}^{T} \beta A e^{-\alpha t} d t\right]=C I_{0}+\frac{C \beta A}{\alpha}\left(e^{-\alpha t_{1}}-e^{-\alpha T}\right) .
$$

Deterioration cost is

$$
D C=C\left[I_{0}-\int_{0}^{t_{1}} D(t) d t\right]=C I_{0}+\frac{C A}{\alpha}\left(e^{-\alpha t_{1}}-1\right) .
$$

Therefore, the total inventory cost is given by

$$
\begin{aligned}
T C= & O C+P C+H C+S C+L S C+D C=C_{0}+\left[C I_{0}+\frac{C \beta A}{\alpha}\left(e^{-\alpha t_{1}}-e^{-\alpha T}\right)\right] \\
& +\left[I_{0} t_{1} a-\frac{a A}{\alpha^{2}}\left(e^{-\alpha t_{1}}-1+\alpha t_{1}\right)+A a \theta \sum_{n=3}^{\infty} \frac{\alpha^{n-3} t_{1}^{n+1}}{(n-2) ! n(n+1)}\right] \\
& -C_{s} \frac{A \beta}{\alpha}\left[\frac{\left(e^{-\alpha t_{1}}-e^{-\alpha T}\right)}{\alpha}+e^{-\alpha t_{1}}\left(t_{1}-T\right)\right]+\frac{S A(1-\beta)}{\alpha}\left(e^{-\alpha t_{1}}-e^{-\alpha T}\right)+\left[C I_{0}+\frac{C A}{\alpha}\left(e^{-\alpha t_{1}}-1\right)\right] .
\end{aligned}
$$


Our aim is to minimize total inventory cost corresponding to decision variables. In order to show the total cost is minimum, it is essential to test the convexity of the cost function defined by Eq. (9).

Differentiating Eq. (9) partially w.r.t. $t_{1}$ and T, we get

$$
\begin{aligned}
\frac{\partial(T C)}{\partial t_{1}}= & e^{-\alpha t_{1}}\left[\frac{a A}{\alpha}-C \beta A-S A(1-\beta)+C_{s} A \beta\left(t_{1}-T\right)-C A\right] \\
& +I_{0} a+\frac{a A}{\alpha}+A a \theta \sum_{n=3}^{\infty} \frac{\alpha^{n-3} t_{1}^{n}}{(n-2) ! n} \\
\frac{\partial^{2}(T C)}{\partial t_{1}^{2}}= & e^{-\alpha t_{1}}\left[C \beta A \alpha-a A+S A \alpha(1-\beta)+C_{s} A \beta+C A \alpha\right]-C_{s} A \beta \alpha\left(t_{1}-T\right) e^{-\alpha t_{1}}+A a \theta \sum_{n=3}^{\infty} \frac{\alpha^{n-3} t_{1}^{n-1}}{(n-2) !} \\
\frac{\partial(T C)}{\partial T}= & e^{-\alpha T}\left[C \beta A-\frac{C_{s} A \beta}{\alpha}+S A(1-\beta)\right]+\frac{C_{s} A \beta}{\alpha} e^{-\alpha t_{1}} \\
\frac{\partial^{2}(T C)}{\partial T^{2}}= & e^{-\alpha T}\left[C \beta A \alpha+C_{s} A \beta+S A \alpha(1-\beta)\right] \\
\frac{\partial^{2}(T C)}{\partial T \partial t_{1}}= & \frac{\partial^{2}(T C)}{\partial t_{1} \partial T}=-C_{s} A \beta e^{-\alpha t_{1}}
\end{aligned}
$$

Solving Eq. (12), $\frac{\partial(T C)}{\partial T}=0$ yields,

$$
e^{-\alpha T}\left[C \beta A-\frac{C_{s} A \beta}{\alpha}+S A(1-\beta)\right]+\frac{C_{s} A \beta}{\alpha} e^{-\alpha t_{1}}=0 \Rightarrow t_{1}=T-\frac{1}{\alpha} \log \left\{1-R_{0}\right\}
$$

$\log \left\{1-R_{0}\right\}$ is valid for $\left|R_{0}\right|<1$, Where $R_{0}=\frac{\alpha}{C_{s}}\left\{C+\frac{S(1-\beta)}{\beta}\right\}$

Hessian matrix is

$$
\begin{gathered}
H\left(T, t_{1}\right)=\left[\begin{array}{ll}
\frac{\partial^{2}(T C)}{\partial t_{1}^{2}} & \frac{\partial^{2}(T C)}{\partial t_{1} \partial T} \\
\frac{\partial^{2}(T C)}{\partial T \partial t_{1}} & \frac{\partial^{2}(T C)}{\partial T^{2}}
\end{array}\right] \\
D_{3}=\left|\begin{array}{cc}
\frac{\partial^{2}(T C)}{\partial t_{1}^{2}} & \frac{\partial^{2}(T C)}{\partial t_{1} \partial T} \\
\frac{\partial^{2}(T C)}{\partial T \partial t_{1}} & \frac{\partial^{2}(T C)}{\partial T^{2}}
\end{array}\right|=\left(\frac{\partial^{2}(T C)}{\partial t_{1}^{2}}\right)\left(\frac{\partial^{2}(T C)}{\partial T^{2}}\right)-\left(\frac{\partial^{2}(T C)}{\partial t_{1} \partial T}\right)^{2} \\
\quad=\left[\begin{array}{ll}
e^{-\alpha t_{1}} & \left.\left\{C \beta A \alpha-a A+S A \alpha(1-\beta)+C_{s} A \beta+C A \alpha\right\}-C_{s} A \beta \alpha\left(t_{1}-T\right) e^{-\alpha t_{1}}+A a \theta \sum_{n=3}^{\infty} \frac{\alpha^{n-3} t_{1}^{n-1}}{(n-2) !}\right] \\
& *\left[e^{-\alpha T}\left\{C \beta A \alpha+C_{s} A \beta+S A \alpha(1-\beta)\right\}\right]-C_{s}^{2} A^{2} \beta^{2} e^{-2 \alpha t_{1}}
\end{array}\right.
\end{gathered}
$$

Using $t_{1}$ in the above expression, we get,

$D_{3}>0$

Hence, $\frac{\partial^{2}(T C)}{\partial t_{1}^{2}}=D_{1}>0,\left(\frac{\partial^{2}(T C)}{\partial T^{2}}\right)=D_{2}>0$ and $D_{3}>0$. 
As all the principal minor determinants of Hessian matrix are positive, therefore $T C$ is a convex function and attains global minima.

\section{Numerical Illustration}

All the calculations are performed in MATLAB. For illustration, the following numerical values of different parameters are taken as input for numerical and graphical analysis of the model, $A=100, \theta$ $=0.12, \alpha=0.001, \beta=0.3, \mathrm{a}=2, C=50, c_{s}=5, S=10, C_{0}=100, I_{0}=500$.

Here $\left|R_{0}\right|=0.014<1$

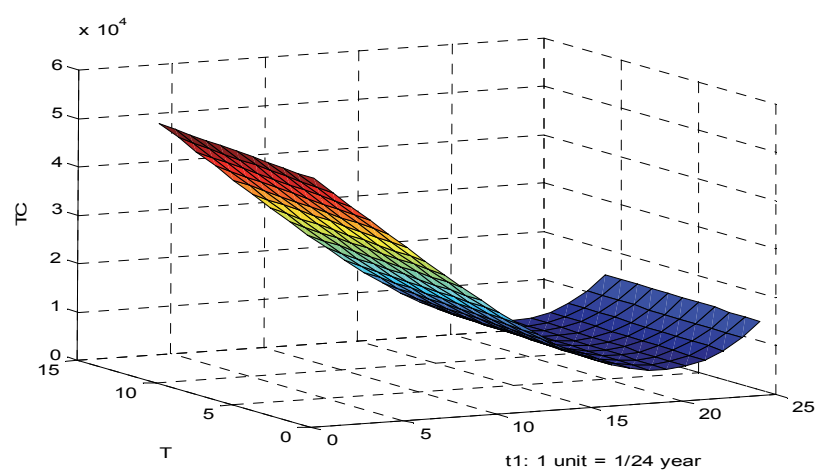

Fig. 1. The plot for the optiaml soution

From the above, we obtain optimal values ast ${ }_{1}=0.833$ year and total cost $(\mathrm{TC})=\mathrm{Rs} 5590$

\section{Case -I}

When $\theta$ follows uniform Distribution, the following numerical values are taken for numerical and graphical representation of the model, $A=100, \theta_{1}=0.12, \theta_{2}=0.62, \alpha=0.001, \beta=0.3, \mathrm{a}=2, C=50, c_{s}$ $=5, S=10, C_{0}=100, I_{0}=500$.

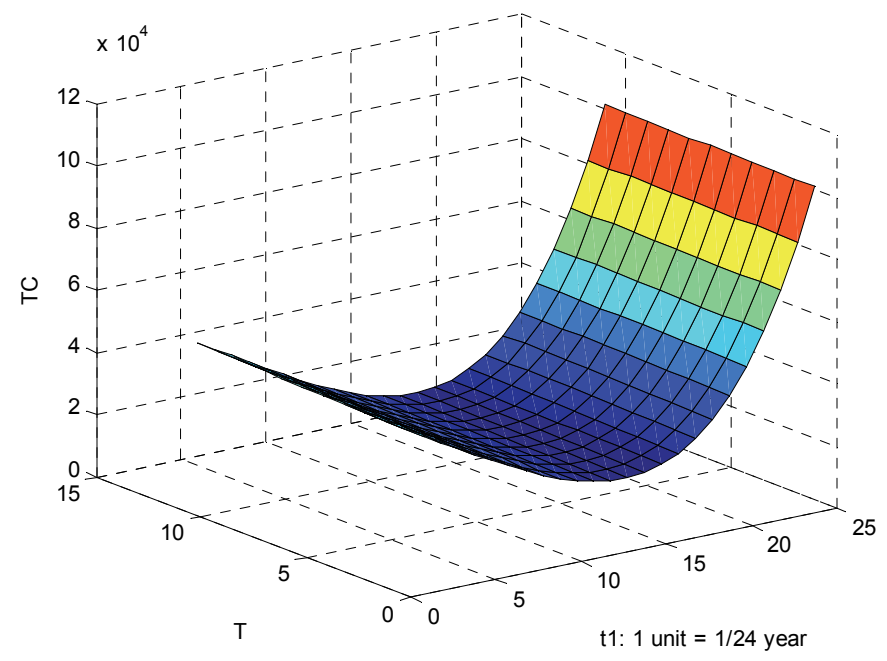

Fig. 2. The optimal solution

Here the optimal values ast $t_{1}=0.5833$ yrs and total cost $(\mathrm{TC})=$ Rs 19920 


\section{Case -II}

When $\theta$ follows triangular Distribution, the following numerical values are taken for numerical and graphical representation of the model, $A=100, \theta_{1}=0.12, \theta_{2}=0.32, \theta_{3}=0.62, \alpha=0.001, \beta=0.3, \mathrm{a}=2$, $C=50, c_{s}=5, S=10, C_{0}=100, I_{0}=500$.

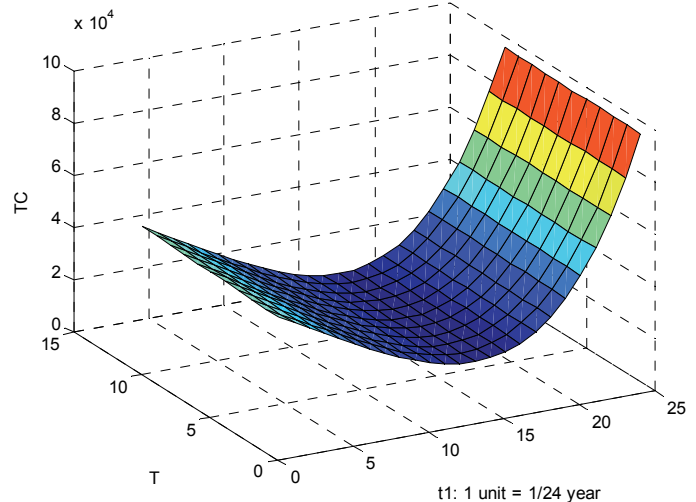

Fig. 3. The optimal solution (Case II)

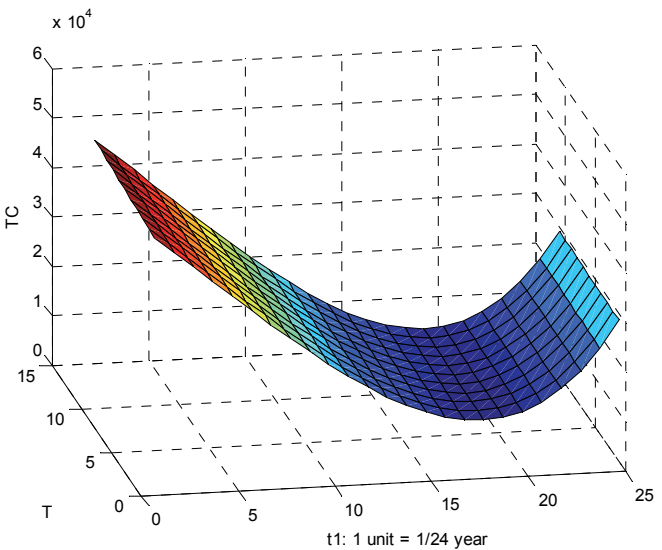

Fig. 4. The optimal solution (Case III)

The optimal values as $\mathrm{t} 1=0.5833$ years and total cost $(\mathrm{TC})=\mathrm{Rs} 19420$.

\section{Case -III}

When $\theta$ follows Beta Distribution, the following numerical values are taken for numerical and graphical representation of the model, $A=100, \alpha_{\theta}=0.12, \beta_{\theta}=0.62, \alpha=0.001, \beta=0.3, \mathrm{a}=2, C=50, c_{s}$ $=5, S=10, C_{0}=100, I_{0}=500$.

The optimal values as $\mathrm{t} 1=0.7500$ years and the total cost $(\mathrm{TC})=$ Rs 9987

From the numerical examples, Figs. (1-4) show the convexity of the function. Among all the optimal solutions obtained in three different cases when deterioration is considered probabilistic, the better optimal solution is obtained in case-III.

\section{Comparison between three different cases of the model under three different distributions:}

The comparison among three different cases of the developed model when deterioration follows three different distributions is given in the following figure.

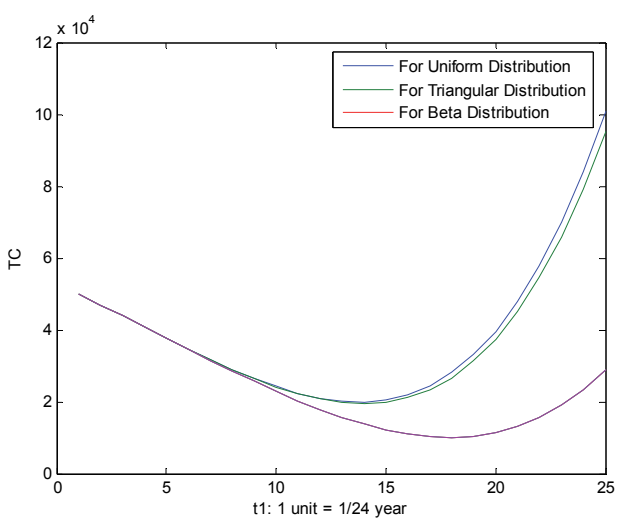

Fig. 5. Total cost with respect to different distributions 


\section{Sensitivity Analysis}

On the basis of the results obtained in figures (2-4), we perform the sensitivity analysis of key parameters $\theta, \alpha$ and $\beta$ as below.

\subsection{Sensitivity analysis for $\theta$ :}

For positive change in the value of the parameter $\theta$, the new value of $\theta$ is evaluated as $\theta=\theta+(1-\theta) *(P \%)$, where, $P$ is the percentage of positive change and for negative change in the value of the parameter $\theta$, the new value of $\theta$ is evaluated as $\theta=\theta-\theta^{*}(N \%)$, where, $N$ is the percentage of negative change.

\subsubsection{Under uniform distribution for $\theta$}

$A=100, \alpha=0.001, \beta=0.3, \mathrm{a}=2, C=50, c_{s}=5, S=10, C_{0}=100, I_{0}=500$

\section{Table 1}

The results of sensitivity analysis under uniform distribution for $\theta$

\begin{tabular}{lcccc}
\hline & $\theta_{1}$ & $\theta_{2}$ & TC (Rs) & $\mathrm{t}_{1}$ (years) \\
\hline$+50 \%$ & 0.56 & 0.810 & 25710 & 0.4583 \\
$+25 \%$ & 0.34 & 0.715 & 23410 & 0.5000 \\
$0 \%$ & 0.12 & 0.62 & 19920 & 0.5833 \\
$-25 \%$ & 0.09 & 0.465 & 16770 & 0.6520 \\
$-50 \%$ & 0.06 & 0.31 & 11780 & 0.7083 \\
\hline
\end{tabular}

\subsubsection{Under triangular Distribution for $\theta$ :}

$A=100, \alpha=0.001, \beta=0.3, \mathrm{a}=2, C=50, c_{s}=5, S=10, C_{0}=100, I_{0}=500$

\section{Table 2}

The results of sensitivity analysis under triangular distribution for $\theta$

\begin{tabular}{llllll}
\hline & $\theta_{1}$ & $\theta_{2}$ & $\theta_{3}$ & TC $(\mathrm{Rs})$ & $\mathrm{t}_{1}$ (years) \\
\hline$+50 \%$ & 0.56 & 0.66 & 0.81 & 25620 & 0.4583 \\
$+25 \%$ & 0.34 & 0.49 & 0.715 & 23220 & 0.5000 \\
$0 \%$ & 0.12 & 0.32 & 0.62 & 19420 & 0.5833 \\
$-25 \%$ & 0.09 & 0.24 & 0.465 & 16270 & 0.6250 \\
$-50 \%$ & 0.06 & 0.16 & 0.31 & 11210 & 0.7083 \\
\hline
\end{tabular}

\subsubsection{Under beta Distribution for $\theta$}

$A=100, \alpha=0.001, \beta=0.3, \mathrm{a}=2, C=50, c_{s}=5, S=10, C_{0}=100, I_{0}=500$

\section{Table 3}

The results of sensitivity analysis under beta distribution for $\theta$

\begin{tabular}{lcccc}
\hline & $\alpha_{\theta}$ & $\beta_{\theta}$ & TC (Rs) & $\mathrm{t}_{1}$ (years) \\
\hline$+50 \%$ & 0.56 & 0.81 & 20970 & 0.5416 \\
$+25 \%$ & 0.34 & 0.715 & 18500 & 0.5833 \\
$0 \%$ & 0.12 & 0.62 & 9987 & 0.7500 \\
$-25 \%$ & 0.09 & 0.465 & 9987 & 0.7500 \\
$-50 \%$ & 0.06 & 0.31 & 9987 & 0.7500 \\
\hline
\end{tabular}

\subsection{Sensitivity analysis for $\alpha$ :}

Following similar procedure described in 6.1, we perform sensitivity analysis for $\alpha$. 
6.2.1. Under uniform distribution for $\alpha$ :

$A=100, \theta_{1}=0.12, \theta_{2}=0.62, \beta=0.3, \mathrm{a}=2, C=50, c_{s}=5, S=10, C_{0}=100, I_{0}=500$

Table 4

The results of sensitivity analysis under uniform distribution for $\alpha$

\begin{tabular}{lccc}
\hline & $\alpha$ & TC (Rs) & $\mathrm{t}_{1}($ years $)$ \\
\hline$+50 \%$ & 0.0015 & 20000 & 0.5833 \\
$+25 \%$ & 0.0013 & 19920 & 0.5833 \\
$0 \%$ & 0.001 & 19920 & 0.5833 \\
$-25 \%$ & 0.00075 & 19880 & 0.5833 \\
$-50 \%$ & 0.0005 & 19840 & 0.5833 \\
\hline
\end{tabular}

\subsubsection{Under triangular distribution for :}

$A=100, \theta_{1}=0.12, \theta_{2}=0.32, \theta_{3}=0.62, \beta=0.3, \mathrm{a}=2, C=50, c_{s}=5, S=10, C_{0}=100, I_{0}=500$

\section{Table 5}

The results of sensitivity analysis under triangular distribution for $\alpha$

\begin{tabular}{llll}
\hline & $\alpha$ & TC(Rs) & $\mathrm{t}_{1}($ years $)$ \\
\hline$+50 \%$ & 0.0015 & 19510 & 0.5833 \\
$+25 \%$ & 0.0013 & 19470 & 0.5833 \\
$0 \%$ & 0.001 & 19420 & 0.5833 \\
$-25 \%$ & 0.00075 & 19380 & 0.5833 \\
$-50 \%$ & 0.0005 & 19340 & 0.5833 \\
\hline
\end{tabular}

\subsubsection{Under beta distribution for}

$A=100, \alpha_{\theta}=0.12, \beta_{\theta}=0.62, \beta=0.3, \mathrm{a}=2, C=50, c_{s}=5, S=10, C_{0}=100, I_{0}=500$

\section{Table 6}

The results of sensitivity analysis under beta distribution for $\alpha$

\begin{tabular}{lccc}
\hline & $\alpha$ & $\mathrm{TC}(\mathrm{Rs})$ & $\mathrm{t}_{1}$ (years) \\
\hline$+50 \%$ & 0.0015 & 10130 & 0.7500 \\
$+25 \%$ & 0.0013 & 10070 & 0.7500 \\
$0 \%$ & 0.001 & 9987 & 0.7500 \\
$-25 \%$ & 0.00075 & 9916 & 0.7500 \\
$-50 \%$ & 0.0005 & 9845 & 0.7500 \\
\hline
\end{tabular}

\subsection{Sensitivity analysis for $\beta$}

Following the procedure mentioned in 6.1 , we perform the sensitivity analysis for $\beta$

\subsubsection{Under uniform distribution for $\beta$}

$A=100, \theta_{1}=0.12, \theta_{2}=0.62, \alpha=0.001, \mathrm{a}=2, C=50, c_{s}=5, S=10, C_{0}=100, I_{0}=500$

\section{Table 7}

The results of sensitivity analysis under uniform distribution for $\beta$

\begin{tabular}{lccc}
\hline & $\beta$ & TC (Rs) & $\mathrm{t}_{1}($ years $)$ \\
\hline$+50 \%$ & 0.4500 & 17610 & 0.5833 \\
$+25 \%$ & 0.3750 & 18770 & 0.5833 \\
$0 \%$ & 0.3 & 19920 & 0.5833 \\
$-25 \%$ & 0.2250 & 21080 & 0.5833 \\
$-50 \%$ & 0.1500 & 22230 & 0.5833 \\
\hline
\end{tabular}


6.3.2. Under triangular distribution for $\beta$ :

$A=100, \theta_{1}=0.12, \theta_{2}=0.32, \theta_{3}=0.62, \alpha=0.001, \mathrm{a}=2, C=50, c_{s}=5, S=10, C_{0}=100, I_{0}=500$

Table 8

The results of sensitivity analysis under triangular distribution for $\beta$

\begin{tabular}{lccc}
\hline & $\beta$ & TC (Rs) & $\mathrm{t}_{1}$ (years) \\
\hline$+50 \%$ & 0.4500 & 17110 & 0.5833 \\
$+25 \%$ & 0.3750 & 18270 & 0.5833 \\
$0 \%$ & 0.3 & 19420 & 0.5833 \\
$-25 \%$ & 0.2250 & 20580 & 0.5833 \\
$-50 \%$ & 0.1500 & 21730 & 0.5833 \\
\hline
\end{tabular}

6.3.3. Under beta distribution for $\beta$ :

$A=100, \alpha_{\theta}=0.12, \beta_{\theta}=0.62, \alpha=0.001, \beta=0.3, \mathrm{a}=2, C=50, c_{s}=5, S=10, C_{0}=100, I_{0}=500$

Table 9

The results of sensitivity analysis under beta distribution for $\beta$

\begin{tabular}{lccc}
\hline & $\beta$ & TC (Rs) & Time(years) \\
\hline$+50 \%$ & 0.4500 & 7603 & 0.7500 \\
$+25 \%$ & 0.3750 & 8795 & 0.7500 \\
$0 \%$ & 0.3 & 9987 & 0.7500 \\
$-25 \%$ & 0.2250 & 11180 & 0.7500 \\
$-50 \%$ & 0.1500 & 12370 & 0.7500 \\
\hline
\end{tabular}

Sensitivity analysis of the parameters is discussed in Tables (1-9). On the basis of the sensitivity analysis, the following observations are made.

From Table 1, when the deterioration rate follows uniform distribution and other parameters remain same, it is seen that with increase in the rate of deterioration, total inventory cost increases and occurrence shortage is earlier. The reverse event is observed with the negative change in deterioration rate. Thus, the total cost is reduced in case of negative change in the deterioration. Table 2 and Table 3 , when deterioration follows triangular and beta distribution, respectively, show similar events in case of total cost and time of occurrence of shortages. From Table 4, when we make positive or negative changes in scaling parameter under the uniform distribution keeping other system parameters with the same values, total cost increases for positive changes and decreases for negative changes but there is no change in occurrence of shortages. Table 5 and Table 6 discuss sensitivity analysis for scaling parameter when deterioration follows triangular and beta distributions, respectively. It is also observed that with positive change, total cost increases and with negative change, total cost decreases with no change in occurrence of shortages. Further, it is also observed that the occurrence of shortages remains the same under triangular and uniform distributions, however Table 6 shows that the occurrence of shortage is a bit later than that of the observed in Table 4 and Table 5.

Table 7, Table 8, and Table 9 light on sensitivity analysis when backlogging rate is changed in both positive and negative directions. The positive change in the value of backlogging rate, total cost decreases and negative change in the value of backlogging rate, total cost increases. In both the cases of change in backlogging rate, there is no effect on the occurrence of shortages.

\section{Conclusion}

The proposed model considering probabilistic deterioration was an extension of existing models in literature where demand was not considered as negative exponential. It is seen that total cost, minimizes when deterioration follows the beta distribution. So far as author's knowledge is concerned, such type of model has not been reported in literature. The developed model can be further extended by taking 
complete backlogging, different type of demand like stock-dependent demand, ramp-type demand etc. and also for two warehouses.

\section{Acknowledgement}

Authors sincerely acknowledge the support of UGC-SAP, Mathematics(F.510/5/DRS/2011(SAP-I)) provided by University Grant Commission, New Delhi to Department of Mathematics, Assam University, Silchar.

\section{References}

Basu, M., Sinha, S., Kalyani, N., \& Bengal, W. (2007). An inflationary inventory model with time dependent demand with Weibull distribution deterioration and partial backlogging under permissible delay in payments.Control and Cybernetics, 36(1), 203.

Bhunia, A., \& Shaikh, A. (2011). A deterministic model for deteriorating items with displayed inventory level dependent demand rate incorporating marketing decisions with transportation cost. International Journal of Industrial Engineering Computations, 2(3), 547-562.

Bhunia, A. K., Shaikh, A. A., Sharma, G., \& Pareek, S. (2015). A two storage inventory model for deteriorating items with variable demand and partial backlogging. Journal of Industrial and Production Engineering, 32(4), 263-272.

Chen, J. M. (1998). An inventory model for deteriorating items with time-proportional demand and shortages under inflation and time discounting.International Journal of Production Economics, 55(1), 21-30.

Cheng, M., Zhang, B., \& Wang, G. (2011). Optimal policy for deteriorating items with trapezoidal type demand and partial backlogging. Applied Mathematical Modelling, 35(7), 3552-3560.

Chou, W. S., \& Julian, P. (2015). Inventory system of deteriorating items with exponential declining demand and partial backlogging. Journal of Interdisciplinary Mathematics, 18(1-2), 89-96.

Dave, U., \& Patel, L. K. (1981). (T, S i) policy inventory model for deteriorating items with time proportional demand. Journal of the Operational Research Society, 32(2), 137-142.

Ghare, P. M., \& Schrader, G. F. (1963). A model for exponentially decaying inventory. Journal of industrial Engineering, 14(5), 238-243.

Goswami, A., \& Chaudhuri, K. S. (1992). An economic order quantity model for items with two levels of storage for a linear trend in demand. Journal of the Operational Research Society, 43(2), 157167.

Goyal, S. K., \& Giri, B. C. (2001). Recent trends in modeling of deteriorating inventory. European Journal of Operational Research, 134(1), 1-16.

Hariga, M. A. (1995). Lot sizing models for deteriorating items with time-dependent demand. International journal of systems science, 26(12), 2391-2401.

Khurana, D., \& Chaudhary, R. (2016). Optimal pricing and ordering policy for deteriorating items with price and stock dependent demand and partial backlogging. Uncertain Supply Chain Management, 4(4), 307-318.

Kumar, S., \& Rajput, U. S. (2016). A Probabilistic Inventory Model for Deteriorating Items with Ramp Type Demand Rate under Inflation. American Journal of Operational Research, 6(1), 16-31.

Latha, K. M., \& Uthayakumar, R. (2014). An Inventory Model for Increasing Demand with Probabilistic Deterioration, Permissible Delay and Partial Backlogging. International Journal of Information and Management Sciences,25(4), 297-316.

Lee, Y. P., \& Dye, C. Y. (2012). An inventory model for deteriorating items under stock-dependent demand and controllable deterioration rate.Computers \& Industrial Engineering, 63(2), 474-482.

Liao, J. J., \& Huang, K. N. (2010). Deterministic inventory model for deteriorating items with trade credit financing and capacity constraints.Computers \& Industrial Engineering, 59(4), 611-618. 
Manna, S. K., \& Chaudhuri, K. S. (2006). An EOQ model with ramp type demand rate, time dependent deterioration rate, unit production cost and shortages. European Journal of Operational Research, 171(2), 557-566.

Ouyang, L. Y., Wu, K. S., \& Cheng, M. C. (2013). An inventory model for deteriorating items with exponential declining demand and partial backlogging. Yugoslav Journal of Operations Research ISSN: 0354-0243 EISSN: 2334-6043, 15(2).

Palanivel, M., Priyan, S., \& Uthayakumar, R. (2015). An inventory model with finite replenishment, probabilistic deterioration and permissible delay in payments. Journal of Management Analytics, 2(3), 254-279.

Palanivel, M., \& Uthayakumar, R. (2014). An EPQ model with variable production, probabilistic deterioration and partial backlogging under inflation.Journal of Management Analytics, 1(3), 200223.

Rao, L.A., Rao, B.N., \& Kumar, R. (2014).Some EOQ model for Weibull deterioration items with selling price dependent demand. International Journal of Soft Computing and Engineering 4(1),5156.

Shah, N. H. (1998). A discrete-time probabilistic inventory model for deteriorating items under a known price increase. International journal of systems science, 29(8), 823-827.

Shah, N. H., \& Pandey, P. (2009). Deteriorating inventory model when demand depends on advertisement and stock display. International Journal of Operations Research, 6(2), 33-44.

Sarkar, B., \& Sarkar, S. (2013). An improved inventory model with partial backlogging, time varying deterioration and stock-dependent demand. Economic Modelling, 30, 924-932.

Sarkar, M., \& Sarkar, B. (2013). An economic manufacturing quantity model with probabilistic deterioration in a production system. Economic Modelling,31, 245-252.

Sarkar, B. (2013). A production-inventory model with probabilistic deterioration in two-echelon supply chain management. Applied Mathematical Modelling, 37(5), 3138-3151.

Singh, T., \& Pattnayak, H. (2013). An EOQ inventory model for deteriorating items with varying trapezoidal type demand rate and Weibull distribution deterioration. Journal of Information and Optimization Sciences, 34(6), 341-360.

Tripathi, R., \& Kumar, M. (2014). A new model for deteriorating items with inflation under permissible delay in payments. International Journal of Industrial Engineering Computations, 5(3), 365-374.

Wang, T. Y., \& Chen, L. H. (2001). A production lot size inventory model for deteriorating items with time-varying demand. International Journal of Systems Science, 32(6), 745-751.

Wee, H. M., \& Law, S. T. (1999). Economic production lot size for deteriorating items taking account of the time-value of money. Computers \& Operations Research, 26(6), 545-558.

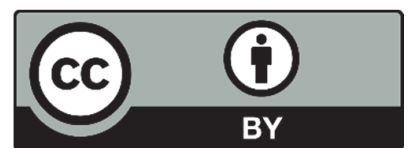

(C) 2016 by the authors; licensee Growing Science, Canada. This is an open access article distributed under the terms and conditions of the Creative Commons Attribution (CC-BY) license (http://creativecommons.org/licenses/by/4.0/). 